\title{
Erratum to: Identification of N-Hexadecanoyl-L-homoserine lactone (C16-AHL) as signal molecule in halophilic bacterium Halomonas smyrnensis AAD6
}

Gennaro Roberto Abbamondi ${ }^{1}$ - Salim Suner ${ }^{2}$ - Adele Cutignano ${ }^{1}$ - Laura Grauso ${ }^{1}$.

Barbara Nicolaus ${ }^{1} \cdot$ Ebru Toksoy Oner $^{3} \cdot$ Giuseppina Tommonaro $^{1}$

Published online: 1 April 2016

(C) Springer-Verlag Berlin Heidelberg and the University of Milan 2016

Erratum to: Ann Microbiol

DOI 10.1007/s13213-016-1206-6

The original version of this article unfortunately contained an error in the article title which is now corrected in this article.

The online version of the original article can be found at http://dx.doi.org/ 10.1007/s13213-016-1206-6.

\footnotetext{
Giuseppina Tommonaro gtommonaro@icb.cnr.it

1 Institute of Biomolecular Chemistry, National Research Council of Italy, Via Campi Flegrei, 34, Pozzuoli, NA, Italy

2 IBSB, Biology Department, Marmara University, Goztepe Campus, 34722 Istanbul, Turkey

3 IBSB, Bioengineering Department, Marmara University, Goztepe Campus, 34722 Istanbul, Turkey
} 